\title{
A systematic review of the treatment of phosphorus in biogeochemical and ecological models
}

\author{
Barbara J. Robson \\ CSIRO Land and Water, Black Mountain \\ Email: barbara.robson@csiro.au
}

\begin{abstract}
Aquatic biogeochemical and ecological models have become increasingly detailed, both in resolution and in the number of processes and components represented. It is timely to pause and take stock of these models. Do these models accurately reflect our current understanding of the biogeochemistry of aquatic systems? Is their predictive performance improving? Are they improving in the range of system properties and behaviours that can be predicted? Where there is variety in approaches or algorithms, can we demonstrate that one method is better than another and should be preferred? This review begins this process, focusing on how phosphorus cycles are represented in models of aquatic systems.
\end{abstract}

A systematic review of 71 distinct published biogeochemical and ecological models of aquatic systems in 167 applications finds:

- Lake models and marine models are very similar, while river and catchment models differ. This appears largely to be due to different traditions within modelling communities rather than real differences in biogeochemical processes.

- River models tend to have simpler representations of phosphorus than lake or marine models.

- The performance of river models is usually quantitatively assessed using standard metrics $(77 \%$ of publications include some performance metrics), while this is usually not the case for lake models (35\% include some quantitative metric) or marine models (only $29 \%$ ).

- Across all three domains, models are becoming more complex over time (Figure 1), but there is no clear evidence that this is improving the predictive performance of models.

The appropriate degree of model complexity depends on a number of factors, including the resources and data available to support the model and the purpose for which the model is being developed. Simpler models can be more rigorously calibrated and evaluated and may have just as much predictive capacity, while physiologically-based models, which are usually more complex, may be more generalisable and better able to anticipate unexpected responses and emergent properties of the system.

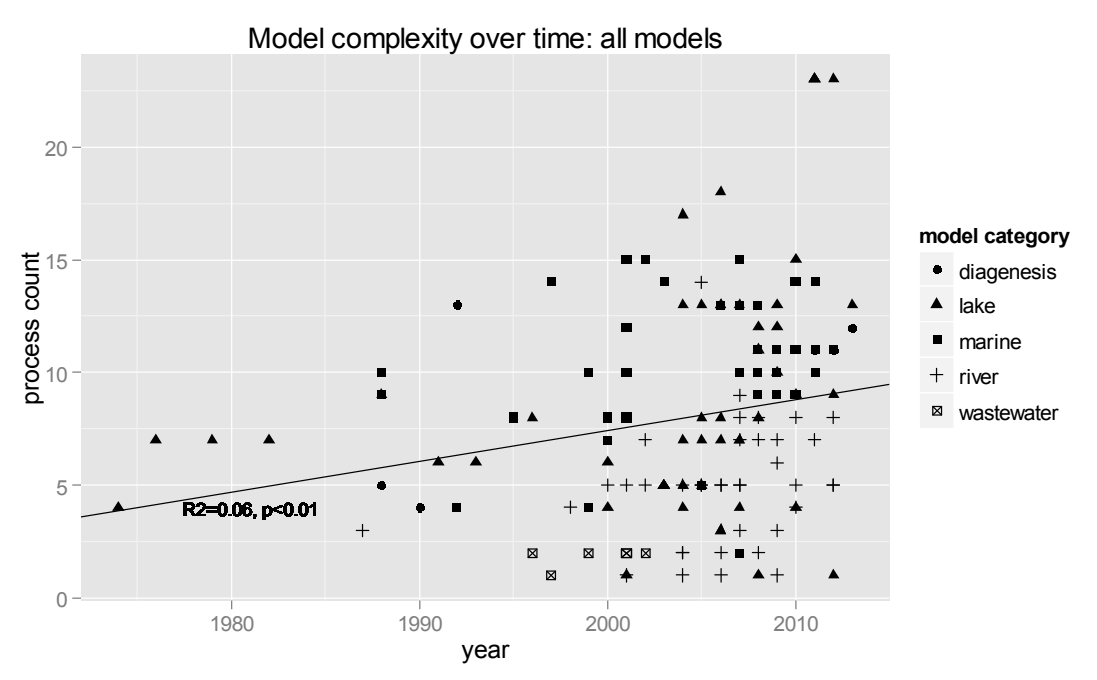

A range of phosphorus papers not included in current models is discussed, including the biogeochemistry of organic phosphorus, the biogeochemical implications of flow through sediments, and sediment drying and re-wetting. In some aquatic environments, these processes are likely to be important. It is concluded that a broader community toolkit of model algorithms is required.

Figure 1 Model complexity over time.

Keywords: Complexity, model assessment, modelling communities, ecological models, water quality, biogeochemistry 
Robson, A systematic review of the treatment of phosphorus in biogeochemical and ecological models

\section{INTRODUCTION}

This paper presents a systematic review of 167 published aquatic modelling papers that include aspects of the phosphorus cycle. The models are compared in terms of how they represent phosphorus processes and how the complexity of phosphorus cycle modelling is changing over time. I will discuss how representations vary between sub-disciplines (lotic and lentic limnological versus oceanographic modelling), how well aquatic ecosystem models are currently being evaluated. Finally, I will discuss some of the processes not included in most current phosphorus models and conclude with some general recommendations for the future.

\section{METHODS}

71 distinct models of aquatic water quality and ecology are assessed in a total of 167 model development and application papers from the published literature. An ad hoc selection process favoured newer publications and widely used models. The total includes 46 applications of lake and reservoir models, 35 of coastal and marine models (including models of estuaries), 36 of catchment and river models, 5 wetland models and, for purposes of comparison, 5 sediment diagenesis models and 3 process-based models of biological wastewater treatment systems. Models were compared in both qualitative and quantitative terms. In assessing model complexity, I have counted one "complexity point" for inclusion of each phosphorus component or process included in each of five categories (detrital, plant, animal, benthic sediment and abiotic processes). One point is assigned for inclusion of multiple phytoplankton groups, regardless of the total number, and one point is assigned for inclusion of "other animals", regardless of whether this is a single fish or an entire foodweb.

\section{HOW IS THE AQUATIC PHOSPHORUS CYCLE REPRESENTED IN MODELS?}

\subsection{Water-column processes}

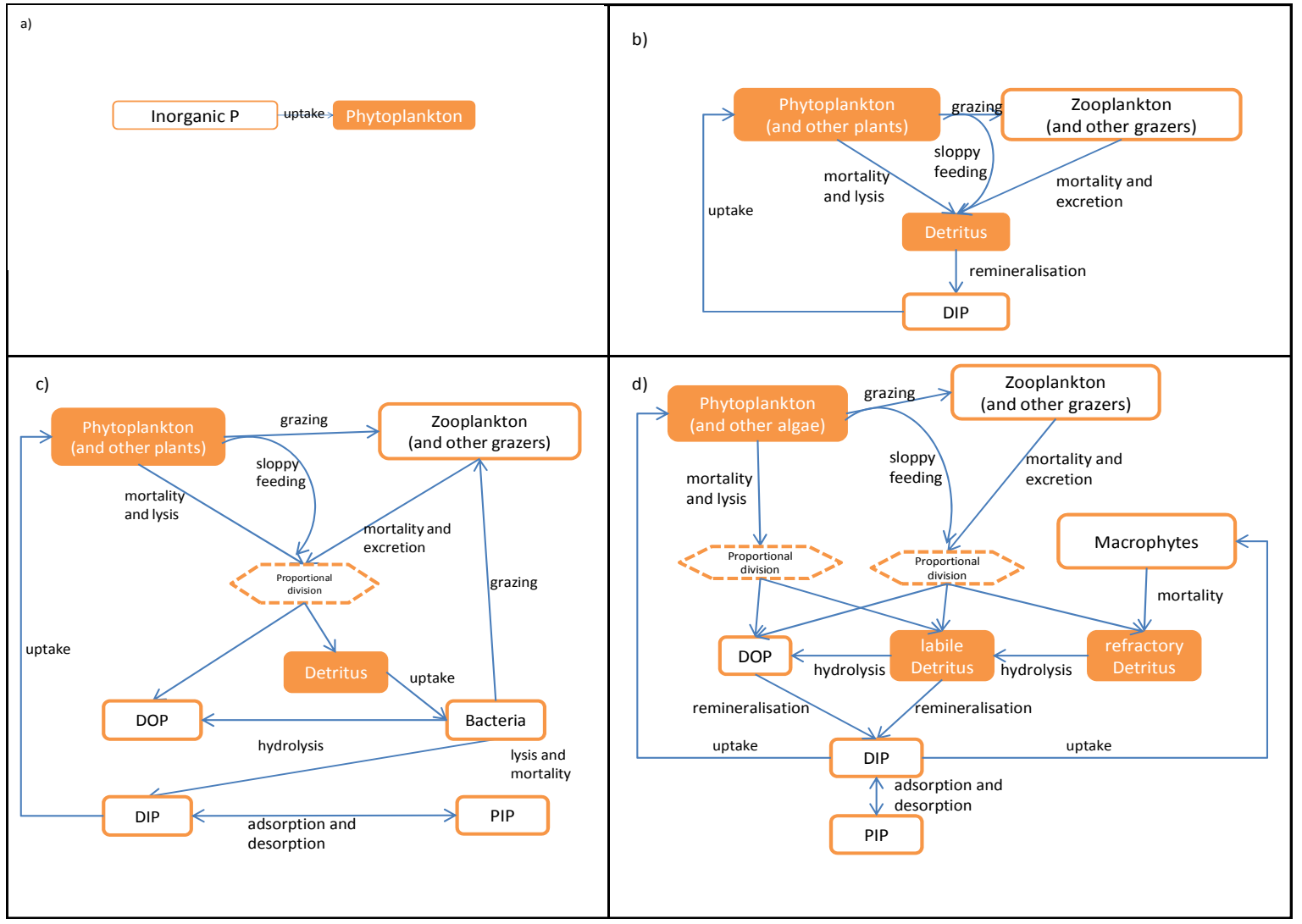

Figure 2 Four common representations of biogeochemical processing of phosphorus in the water column of aquatic systems; a) Simple model including only algal and inorganic phosphorus; b) Classic NPZD model (Elliott et al. 2000); c) Explicit representation of bacterial biomass, division of organic phosphorus into particulate and dissolved components and addition of a particulate inorganic phosphorus (or sediment-adsorbed phosphorus) component (Garnier et al. 2005). d) A typical more complex model, with additional sources of detritus and division of organic phosphorus into two pools of differing lability (Wild-Allen et al. 2011). Some of the examples cited also include components and processes not included in these figures.

Aquatic biogeochemical models may represent the phosphorus cycle in any of several ways, differing largely in the number of components (phosphorus stores) and processes (phosphorus transformations) included. Four 
Robson, A systematic review of the treatment of phosphorus in biogeochemical and ecological models

examples of conceptual representation of water-column phosphorus cycling as embodied in mechanistic models are given in Figure 2.

The phytoplankton and zooplankton/grazer compartments are commonly divided into several groups, either size-based (Baird 2010), taxonomically based (Reynolds et al. 2001), or taking the hybrid "functional groups" approach. This allows a more detailed representation of the plankton dynamics of the system, such as representations of phytoplankton succession (Hearn and Robson 2001), transitions at estuarine interfaces (Chan et al. 2002), or occurrence of harmful algal blooms (Robson and Hamilton 2003), but it also allows more realistic simulation of overall system dynamics, as the plankton communities adapt to changing environmental conditions (Baird 2010). Another approach is to use "goal function" models, in which a single phytoplankton component changes its properties as conditions change, maximising a function such as the calculated exergy of the system (Bendoricchio and Jorgensen 1997). Though theoretically attractive, this approach is relatively little-used; it is more difficult to implement than a multiple-group approach, while retaining some of the limitations of a single-group model.

Benthic filter feeders have often been found to be particularly important controls on phosphorus cycling and algal blooms in lake ecosystem models, so these are explicitly included as grazers in several models (Meyers et al. 2000).

Most models do not explicitly simulate bacterial biomass (Figure 2c), but a growing number of models do so (Figure 2d). These are rarely validated against observations of bacterial abundance, but it is argued that they allow more realistic system dynamics, for example, by simulating the impact of microbial processing on water-column stoichiometry (Li et al. 2013). Another advantage may be the ability to more easily represent positive feedbacks between concentrations of organic matter and degradation rates (Lønborg et al. 2009). A few models include more than one functional group of bacteria; for example, aerobic and anaerobic groups (Kaufman and Borrett 2010), sulfate-reducing and non sulfate-reducing (Prokopkin et al. 2010), or nitrifying and denitrifying bacteria.

\subsection{Benthic processes}

Although early lake models tended to omit interactions between the water column and benthic sediments, and this is still true of most deep ocean models and some river models, modern lake and coastal models do include interactions at the sediment interface. There are essentially three approaches to this:

1) Represent the benthos as a boundary condition, applying specified, calibrated phosphorus fluxes that may either be fixed as in PROTECH (Elliott et al. 2000) or vary as a function of temperature, dissolved oxygen and DIP in the bottom layer of water, as in simpler implementations of CAEDYM (e.g. Robson and Hamilton 2004).

2) Duplicate water-column components and processes in one or more sediment layers (often a surface aerobic layer and a bottom anaerobic layer), specifying different parameter values to control the rates of remineralisation or hydrolysis in aerobic and anaerobic layers and either omitting phytoplankton or replacing them with benthic microalgae/microphytobenthos in the sediment layer. Examples of models that take this approach include EMS (Wild-Allen et al. 2011), CE-QUAL-W2 (Cole and Wells 2008) and recent implementations of ERSEM (Allen and Clarke 2007).

3) Incorporate a complete sediment diagenesis model, simulating redox conditions as a function of concentrations of relevant ions (e.g. $\mathrm{Fe}^{2+}, \mathrm{Fe}^{3+}, \mathrm{Ca}^{2+}, \mathrm{S}^{2-}, \mathrm{SO}_{4}{ }^{2-}, \mathrm{H}^{+}$), and including representations of processes such as precipitation of apatite phosphates. Only a very few models take this approach - the more complex implementations of CAEDYM (Hipsey and Busch 2012) being a key example.

Approach (1) has the advantage of simplicity and does not require detailed characterisation of the benthos. Its great disadvantage is that the resulting parameterisation is highly site-specific and the model will not be able to simulate long-term changes that alter the state of the sediments. If sediment fluxes are not measured, there is also a danger that the sediment flux rates become a "fudge factor" in calibrating such models, as they have a broad range of reasonable values and often a strong influence on predicted water-column concentrations.

Approach (2) avoids these problems and allows conservation of mass within the system as a whole, at a cost of an increase in the number of parameters included and the initialisation requirements of the model.

Approach (3) is strongly driven by a geochemical conceptualisation and allows a stronger representation of abiotic chemical processes that bind inorganic phosphorus in sediments, but results in a very complex, computationally expensive and data-hungry model, as it requires a raft of additional components to be included in the model, both within the water-column and multiple sediment layers (which may be highly 
spatially heterogeneous). This approach may be indicated when modelling systems with iron-rich sediments, in which co-precipitation of phosphorus may be an important removal mechanism (Baldwin et al. 2002).

\subsection{Physical framework}

Aquatic biogeochemical and ecological models are typically embedded within hydrologic or hydrodynamic models. These range from simple box models of lakes (Imboden 1974), through multiple box models of seas and network models of rivers, through one dimensional, vertically resolved models of lakes, one dimensional, longitudinally resolved models of rivers (which may be either simple hydrologic models or physics-based hydraulic models), two-dimensional, spatially resolved models of catchments or aquatic systems (sometimes with additional layers to represent groundwater storages) and two-dimensional, vertically resolved river and estuary models, to full three-dimensional, baroclinic modelling systems.

Greater resolution and dimensionality is becoming

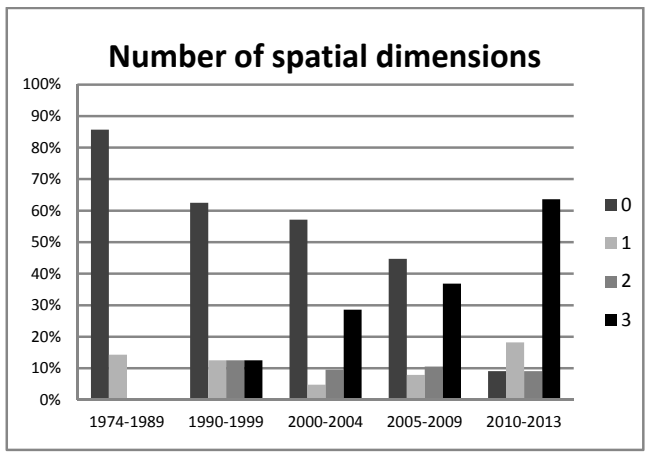

Figure 3 Number of spatial dimensions in 96 lake and marine models, grouped by year of publication. Models with fewer than 12 boxes arranged two-dimensionally or fewer than 5 boxes arranged as vertical layers are counted as zero-

increasingly common as computing resources improve (Figure 3), but three-dimensional modelling should not always be the default. Three dimensions are sometimes necessary to simulate important physical dynamics, but implementing a three-dimensional model of reasonable resolution is computationally expensive, which limits the options available for parameter estimation, sensitivity analysis and uncertainty analysis, while also making verification less straightforward and reducing the number of scenario runs that can be conducted. Physical processes sometimes dominate biogeochemical and ecological responses and often overwhelm any other considerations in an aquatic system model (Rigosi and Rueda 2012).

\section{HOW DO RIVER MODELS, LAKE MODELS AND MARINE MODELS COMPARE?}

Figure 4 summarises the complexity and relative emphasis of models published in the past decade.

The formulation of lake models and marine models is very similar (in some cases, identical) and both tend to be complex. Catchment-river models are almost universally simpler in their treatment of in-stream processes. Pure catchment models (not included in this systematic review) include no in-stream nutrient processes at all,

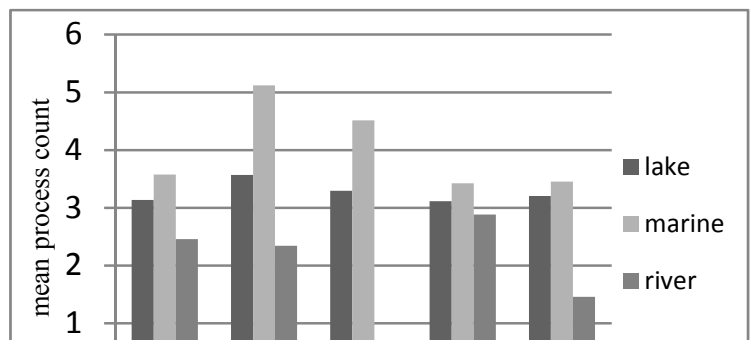

Figure 4 Mean number of phosphorus processes and components included in each of five categories in models published since 2002. Detrital Plant Animal Abiotic Benthic assuming that landscape generation processes are dominant in determining river nutrient loads.

\section{HOW ARE MODELS CHANGING OVER TIME?}

Figure 1 shows how the complexity of models included in our systematic review has changed over time. Complexity in all sub-disciplines is increasing.

In some cases, these increases in complexity are a direct response to calls for increased realism. As noted by Flynn (2005), however, this is not always the case, as it is also common for new components to be added to models without pausing to examine how existing components can be made to better reflect a biological understanding of the system.

\section{MODEL EVALUATION}

Table 1 summarises reporting statistics for the more recent (i.e. post-2002) papers analysed in the present review, showing that little has changed in the decade since the review of marine models conducted by Arhonditsis and Brett (2004). Only 30\% of marine modelling papers and 35\% of lake modeling papers report any statistical measure of model performance. When lake and marine modellers do report performance statistics, these are not always for independent validation data sets: calibration and verification were conflated in about half the papers assessed for this analysis. It is rare for statistics to be reported for more than a selected few of the variables (often chlorophyll $a$ and total phosphorus) simulated by the model. 
Robson, A systematic review of the treatment of phosphorus in biogeochemical and ecological models

Table 1 Performance reporting in models published since 2003 included in this analysis. Bennett et al. (2013) describe the range of statistical measures available and discuss their utility in environmental modelling.

\begin{tabular}{|c|c|c|c|c|}
\hline & $\begin{array}{l}\begin{array}{l}\text { Number of papers } \\
\text { reviewed } \\
\text { (published }\end{array} \\
\text { since 2003) }\end{array}$ & $\begin{array}{l}\% \text { reporting } \\
\text { performance } \\
\text { metrics }\end{array}$ & $\begin{array}{l}\text { Most commonly } \\
\text { reported metrics }\end{array}$ & Other metrics encountered \\
\hline Marine models & 28 & $29 \%$ & $r^{2}$ & $\begin{array}{l}\text { skill factor, target diagram, root } \\
\text { mean square error }\end{array}$ \\
\hline Lake models & 43 & $35 \%$ & $\begin{array}{l}r^{2} \text { and root mean } \\
\text { square error }\end{array}$ & $\begin{array}{l}\text { relative error, normalised mean } \\
\text { absolute error, Spearman correlation, } \\
\text { mean absolute error }\end{array}$ \\
\hline River models & 31 & $77 \%$ & $\begin{array}{l}\text { Nash-Sutcliffe } \\
\text { Efficiency, } r^{2} \text {, relative } \\
\text { error }\end{array}$ & $\begin{array}{l}\text { sum of square of normalised } \\
\text { residuals, mean square deviation, } \\
\text { root mean square error, bias, failure } \\
\text { rate, coefficient of error }\end{array}$ \\
\hline
\end{tabular}

The situation is quite different in river modelling, with a clear majority of papers reporting performance statistics for separate (though not always independent) calibration and verification datasets. In many cases, Nash-Sutcliffe efficiency, $\mathrm{r}^{2}$ and relative error (all of which are made available as standard outputs of SWAT tools) are reported for flow, and only a subset of these are reported for phosphorus.

Catchment and river models thus tend to be much simpler than lake and marine models, and more rigorously evaluated. Cultural factors, including differences in the regulatory context of marine, lake and river modelling and differences in the priorities of hydrological journals versus limnological and oceanographic journals, probably explain this disparity.

\section{WHAT IS NOT MODELLED? CHALLENGES AND GAPS}

Today's aquatic biogeochemical models have their roots in management and modelling of harmful algal blooms. These models were designed for mesotrophic to eutrophic, lentic waters. What processes are missing from our current generation of models that might be important in the other contexts?

In oligotrophic (low nutrient) environments, the rate of transfer of dissolved phosphorus across the diffusive boundary layer is likely to be the primary control on the rate at which plants are able to take up phosphorus from the water column. Hearn et al. (2001) present a formulation for modelling of flux-limited nutrient uptake in coral reefs, Stevens et al. (2003) do the same for giant kelp, while Robson (2010) considers fluxlimited nutrient uptake in modelling benthic macroalgae in a tropical river. These formulations, however, have not yet been widely adopted in complete biogeochemical or ecological modelling packages for freshwater systems.

Flow through sediments due to groundwater-surface water interactions, flow through sand ripples, tidal pressure gradients and wave action greatly increases interactions between the water column and sediment pore-water and may enhance microbial activity and rates of many biogeochemical reactions by providing dynamic redox conditions and exposure to reactive particle surfaces. These interactions are not yet generally considered in biogeochemical models, though in some cases, this is compensated for by setting a high dispersion coefficient.

Though many catchment hydrology models include groundwater stores, and models such as SWAT (Vadas and White 2010) do consider transport of dissolved phosphorus through groundwater, most models do not consider groundwater biogeochemistry. Hydrolysis of dissolved organic phosphorus to phosphate, removal of phosphorus through adsorption to soil surfaces or uptake by riparian vegetation, and long time-lags between addition or removal of sources of groundwater nutrient pollution and subsequent delivery to aquatic systems are rarely considered.

Sediments in many aquatic environments are subject to wetting and drying on tidal timescales in coastal environments, seasonal timescales in seasonal rivers and wetlands, and for years at a time on many floodplains. Drying and subsequent rewetting can have complex biogeochemical implications as sediment surfaces switch between anaerobic and aerobic respiration and bacterial communities change. Biogeochemical processing continues when soil is dry, and can result in the release of large quantities of phosphorus immediately after rewetting. At present, even models that simulate the physics of wetting and drying do not simulate biogeochemical processes in dry cells. This is something that probably needs to be considered if we are to accurately simulate phosphorus cycles of floodplains or seasonal wetlands.

Biogeochemical understanding of organic phosphorus in aquatic environments is incomplete, but has been developing rapidly in recent years. Our models do not yet reflect this growing understanding. The origin of organic phosphorus in aquatic environments determines its chemical composition and physical 
Robson, A systematic review of the treatment of phosphorus in biogeochemical and ecological models

characteristics, which in turn affects bioavailability, chemical availability and nutritional quality. This review has not uncovered any examples of biogeochemical models of natural environmental systems that divide organic phosphorus into chemically distinguished components, though some wastewater treatment models do so (Liu et al. 2007).

\section{CONCLUSIONS}

There is a clear separation between marine and lake models on one side (diverse and conceptually sophisticated, but lacking rigour in implementation and assessment) and catchment and river models on the other (tending to neglect important biogeochemical processes, but with more rigorous characterisation of performance). As we move towards integrated catchment-to-ocean modelling, we need to overcome these differences, establishing a consistent approach across the two communities.

As we build the next generation of water quality models, we must:

- Assess the physiological basis of alternative functional forms for phosphorus processes, and reject those than cannot produce ecologically realistic results within the range of conditions for which the models are being applied;

- Interact continually with observational scientists, to ensure that our models reflect the best available systems understanding and to ensure that observational programs are designed that can provide the information needed by our models; and

- Agree on standard metrics and methodologies for performance assessment, so that we can conduct meaningful meta-analyses to identify problems and successes.

As a community, we should be working to build a toolkit of submodels from which we can pick and choose to suit each modelling application. At the same time, we should beware of continuing increases in the complexity of models, as increases in model complexity over the past few decades have not been demonstrated to have substantially improved our predictive capacity. As a rule of thumb, a more complex model should only be used where a simpler model has been demonstrated to be inadequate, and a proposed, more complex formulation should always be thoroughly investigated to ensure that (even in light of the limitations of available data and uncertainties in other parts of the phosphorus cycle) it really does lead to more accurate representation of phosphorus cycling in aquatic ecosystems.

An extended version of this paper, including additional commentary and guidance on algorithm choice and model complexity has been submitted for consideration by Environmental Modelling \& Software (Robson submitted).

\section{ACKNOWLEDGMENTS}

This work was supported by the CSIRO Water for a Healthy Country National Research Flagship. Thanks are due to Kerrie Tomkins for assistance in collating data for systematic review.

\section{REFERENCES}

Allen, J. I. and K. R. Clarke (2007). "Effects of demersal trawling on ecosystem functioning in the North Sea: a modelling study." Marine Ecology Progress Series 336: 63-75. Doi 10.3354/Meps336063.

Arhonditsis, G. B. and M. T. Brett (2004). "Evaluation of the current state of mechanistic aquatic biogeochemical modeling." Marine Ecology Progress Series 271: 13-26. Doi 10.3354/Meps271013.

Baird, M. E. (2010). "Limits to prediction in a size-resolved pelagic ecosystem model." Journal of Plankton Research 32(8): 1131-1146. DOI 10.1093/plankt/fbq024.

Baldwin, D., A. Mitchell and J. Olley (2002). Pollutant-Sediment Interactions: Sorption, Reactivity and Transport of Phosphorus. Agriculture, Hydrology, and Water Quality. H. P. and S. Jarvis. Wallingford, CABI Publishing: 265-280.

Bendoricchio, G. and S. E. Jorgensen (1997). "Exergy as goal function of ecosystems dynamic." Ecological Modelling 102(1): 5-15. Doi 10.1016/S0304-3800(97)00091-4.

Bennett, N. D., B. F. W. Croke, G. Guariso, J. H. A. Guillaume, S. H. Hamilton, A. J. Jakeman, S. MarsiliLibelli, L. T. H. Newham, J. P. Norton, C. Perrin, S. A. Pierce, B. Robson, R. Seppelt, A. A. Voinov, B. D. Fath and V. Andreassian (2013). "Characterising performance of environmental models." Environmental Modelling \& Software 40: 1-20. DOI 10.1016/j.envsoft.2012.09.011.

Chan, T. U., D. P. Hamilton, B. J. Robson, B. R. Hodges and C. Dallimore (2002). "Impacts of hydrological changes on phytoplankton succession in the Swan River, Western Australia." Estuaries 25(6B): 1406-1415. Doi 10.1007/Bf02692234. 
Robson, A systematic review of the treatment of phosphorus in biogeochemical and ecological models

Cole, T. M. and S. A. Wells (2008). CE-QUAL-W2: a two-dimensional, laterally averaged, hydrodynamic and water quality model, version 3.2, U.S. Army Corps of Engineers

Elliott, J. A., C. S. Reynolds and T. E. Irish (2000). "The diversity and succession of phytoplankton communities in disturbance-free environments, using the model PROTECH." Archiv für Hydrobiologie 149(2): 241-258.

Flynn, K. J. (2005). "Castles built on sand: dysfunctionality in plankton models and the inadequacy of dialogue between biologists and modellers." Journal of Plankton Research 27(12): 1205-1210. DOI 10.1093/plankt/fbi099.

Garnier, J., J. Nemery, G. Billen and S. Thery (2005). "Nutrient dynamics and control of eutrophication in the Marne River system: modelling the role of exchangeable phosphorus." Journal of Hydrology 304(1-4): 397-412. DOI 10.1016/j.jhydrol.2004.07.040.

Hearn, C. J., M. J. Atkinson and J. L. Falter (2001). "A physical derivation of nutrient-uptake rates in coral reefs: effects of roughness and waves." Coral Reefs 20(4): 347-356.

Hearn, C. J. and B. J. Robson (2001). "Inter-annual variability of bottom hypoxia in shallow Mediterranean estuaries." Estuarine Coastal and Shelf Science 52(5): 643-657. DOI 10.1006/ecss.2001.0773.

Hipsey, M. R. and B. D. Busch (2012). Lower Lakes Water Quality Recovery Dynamics

Imboden, D. M. (1974). "Phosphorus Model of Lake Eutrophication." Limnology and Oceanography 19(2): 297-304.

Kaufman, A. G. and S. R. Borrett (2010). "Ecosystem network analysis indicators are generally robust to parameter uncertainty in a phosphorus model of Lake Sidney Lanier, USA." Ecological Modelling 221(8): 1230-1238. DOI 10.1016/j.ecolmodel.2009.12.018.

Li, Y., A. M. Waite, G. Gal and M. R. Hipsey (2013). "An analysis of the relationship between phytoplankton internal stoichiometry and water column N:P ratios in a dynamic lake environment." Ecological Modelling 252(0): 196-213. 10.1016/j.ecolmodel.2012.06.021.

Liu, Y., Y. Chen and Q. Zhou (2007). "Effect of initial pH control on enhanced biological phosphorus removal from wastewater containing acetic and propionic acids." Chemosphere 66(1): 123-129. 10.1016/j.chemosphere.2006.05.004.

Lønborg, C., K. Davidson, X. A. Álvarez-Salgado and A. E. J. Miller (2009). "Bioavailability and bacterial degradation rates of dissolved organic matter in a temperate coastal area during an annual cycle." Marine Chemistry 113(3-4): 219-226.

Meyers, M. B., D. M. Di Toro and S. A. Lowe (2000). "Coupling suspension feeders to the Chesapeake Bay eutrophication model." Water Quality and Ecosystems Modeling 1(1-4): 123-140.

Prokopkin, I., W. Mooij, J. Janse and A. Degermendzhy (2010). "A general one-dimensional vertical ecosystem model of Lake Shira (Russia, Khakasia): description, parametrization and analysis." Aquatic Ecology 44(3): 585-618.

Reynolds, C., A. Irish and J. Elliott (2001). "The ecological basis for simulating phytoplankton responses to environmental change (PROTECH)." Ecological Modelling 140(3): 271-291.

Rigosi, A. and F. J. Rueda (2012). "Propagation of uncertainty in ecological models of reservoirs: From physical to population dynamic predictions." Ecological Modelling 247: 199-209. DOI 10.1016/j.ecolmodel.2012.08.022.

Robson, B. J. (2010). How flow and nutrients affect plants and algae in the Daly River, N.T. International Environmental Modelling and Software Society (iEMSs) 2010 International Congress on Environmental Modelling and Software. D. A. Swayne, W. Yang, A. A. Voinov, A. Rizzoli and T. Filatova. Ottawah, Canada, International Environmental Modelling and Software Society (iEMSs)

Robson, B. J. (submitted). "State of the art in modelling of phosphorus cycles in aquatic systems: review, criticisms and commentary." Environmental Modelling \& Software.

Robson, B. J. and D. P. Hamilton (2003). "Summer flow event induces a cyanobacterial bloom in a seasonal Western Australian estuary." Marine and Freshwater Research 54(2): 139-151. Doi 10.1071/Mf02090.

Robson, B. J. and D. P. Hamilton (2004). "Three-dimensional modelling of a Microcystis bloom event in the Swan River estuary, Western Australia." Ecological Modelling 174(1-2): 203-222. DOI 10.1016/j.ecolmodel.2004.01.006.

Stevens, C. L., C. L. Hurd and P. E. Isachsen (2003). "Modelling of diffusion boundary-layers in subtidal macroalgal canopies: The response to waves and currents." Aquatic Sciences 65(1): 81-91. DOI $10.1007 / \mathrm{s} 000270300007$.

Vadas, P. and M. White (2010). "Validating Soil Phosphorus Routines in the SWAT Model."

Wild-Allen, K., P. A. Thompson, J. K. Volkman and J. Parslow (2011). "Use of a coastal biogeochemical model to select environmental monitoring sites." Journal of Marine Systems 88(1): 120-127. DOI 10.1016/j.jmarsys.2011.02.017. 